\title{
Misconceptions and associated errors in the learning of mathematics place value in South African primary schools: A literature review
}

\author{
K M Themane and K Luneta \\ University of Johanneburg \\ Department of Childhood Education
}

\begin{abstract}
Children's learning of place value is critical to their future study of mathematics. However, its learning presents a huge challenge for many learners. As result they develop misconceptions and thencommit errors that become an encumbrance to their understanding of place value. It is therefore important to identify these misconceptions and their associated errors early and help children to overcome them. This article reports the findings from literature on what misconceptions learners display in the learning of place value and how they can best be supported to overcome them. The results show that despite the importance of this topic there are limited studies devoted to its research. The dearth of these studies creates a gap in the study of place value.
\end{abstract}

Keywords: Misconceptions, errors, learning, place value, mathematics, literature review

\begin{abstract}
Introduction
This article presents a review of literature on place value as an important aspect of number sense in mathematics for young children. We examine how place value has been studied worldwide, but with specific reference to South Africa in the past 25 years (1995-2020). Specifically, we focus on the methodological characteristics and publication trends in its study. This focus has translated into the following three questions that we used to guide the search and analysis of the literature: a) What do we know about the types of errors displayed by Grade 3-6 learners in the learning of place value and how has place value been studied in the last 30 years elsewhere in the world, and in South Africa in particular? c) What have the publication trends on the subject been during this period?

The article begins by highlighting the significance of this review in perspective of the previously conducted studies. Then we move onto defining what place value is, followed by a brief description of what misconceptions and associated errors entail. This is followed by an explanation of the methods applied for the literature search and selection, and the results of the search. Finally, we discuss and critique the findings by drawing from Bourdieu's social and cultural theory as an analytical frame. It is hoped that this will enable us to know whether substantial progress has been made in the children's learning of place value or not in South Africa. Finally, the review will make general and context specific recommendations.
\end{abstract}




\section{Significance of the review}

The significance of this review emanates from at least three compelling reasons. First, it is of critical importance for the development of mathematics education to understand the misconceptions and associated errors dispalyed by children in the learning of place value, in particular for the learning of multiple digits in the four operations (additions, substraction, division and multiplication). Second, given the heightened interest in the drive to improve the teaching and learning of mathematics in South Africa, it is imperative to take stock of the research done on place value, especially how it manifests itself among disadvantaged learners from rural primary schools. Third, it is important to do a scoping exercise of this period (1995-2020) around this topic, pointing out its weaknesses and strengths, so that new ways of theorising and researching the topic could be developed.

\section{The concept place value}

Before identifying misconceptions displayed by learners and their associated errors, we need to give a brief discussion of what place value entails. Definitions of place value have a long and protracted history of controversy (Hansen, 2017). These definitions vary in emphasis of certain aspects that make up the concept place value. For example, there are those that elevate its function. For example, Haylock's (2007) definition defines its role in the number system. He argues that place value is important for children to read, write and to order numbers. His definition emphasises its role as an enabler to read numbers with meaning or understanding. For example, he stresses that children should be able to distinguish between tenths and hundredths within a text with ease. In this view, he is supported by a number of scholars in the field of mathematics education (Luneta, 2013; Luneta \& Makonye, 2013; Coles, \& Sinclair, 2017; Benton, Saunders, Kalas, Hoyles \& Noss, 2018).

Another interesting notion of place value is that of van de Walle (2004) that stresses children's understanding when learning place value. He observes that a place value is intended to help children recognise that the position of a digit gives its value when counting forwards or backwards in tens or hundredths from any two-digit or three-digit numbers. This definition is important for two reasons: one, it underlines the criticality of place value in the number system, especially when counting beyond single digit numbers (Browning \& Beauford, 2012). For children to be able to count meaningfully and effectively with complex numbers, they need a strong grounding on place value (Luneta, 2013). Without a sound grounding on place value, children's numeration would descend to regurgitation, which most teachers are prone to subjecting children to.

All the foregoing definitions seem to tilt in favour of learning place value for understanding or conceptualisation rather than algorithmically. This illustrates, among other constructs in learning place value, the importance of language, which has in recent years received considerable attention as a predictor of cognitive development of understanding of place value (Browning \& Beauford, 2012; Scherer, 2014). Without deviating from our argument, in the next section we would like to look into this issue briefly, especially as it concerns children's learning of place value with understanding.

About two decades ago, a study by Rossa (1991) on the influence of language on the learning of place value revealed that language plays an important role in converting numbers from one base to another. The use of the learner's social context (including 
mother tongue instruction) was found to be most helpful in increasing their understanding (Aunio \& Räsänen, 2016).

This foregoing exposition is quite fascinating to us as it also leans towards the learner as the best starting point for learning to take place. These definitions seem to put the learner first before the subject matter (Mundia, 2017). The definitions that have beenexplored so far are biased towards the learner as a point of departure in the teaching of place value, for which we argue in this article (Fuson, 1990; Scherer, 2014). Indeed, from an array of witnesses, it would appear that if learners are adequately supported they can overcome difficulties in the learning of the place value concept. Mastering place value will set learners on the right path to understanding other complex mathematical notations, such as decimal notations of tenths and hundredths in their contexts. They will also be able to locate a number on the number line, and easily convert between centimetres and metres.

When the learner is in the forefront of any definition of place value, we argue, that the learner should be able to distinguish between different combinations of numbers. For example, that in the number 777 , the first 7 refers 700 , the second 7 refers to 70 and the last 7 means the units and the value is $700+70+7$ (Byrge, Smith \& Mix, 2014). The ability to locate the place of a digit in a number, and its value is a key to learning with conceptual understanding.

These definitions carry a constitutive meaning that is a prerequisite for teaching and learning place value for conceptual understanding. Rappaport's (2017) study of students' conceptual understanding using a Video Evaluation Task to record students' work on the double-digit addition problem revealed that the use of videos afforded more information about students' conceptual understanding of place value, which could have otherwise not been achieved through the direct method of instruction. Thus, a learner-centred approach to teaching is best positioned to cultivate conceptual understanding of place value.

An understanding of place value is the most crucial aspect of mathematics that underpins much of the number work undertaken by children (Hansen, 2005; Hansen, (2017). A lack of its understanding may create difficulties that might lead to errors and misconceptions of mathematics in general, and of place value in particular. Without a proper understanding of the concept makes place value a difficult idea to learn, which involves much more than recognising place value parts (Luneta, 2014). Place value is thus, a highly complex and abstract concept for children to grasp easily, especially if introduced too early in their lives (Luneta \& Makonye, 2013; Cooper \& Tomayko, 2011; Hansen, 2005). It is for this reason that proper strategies should be developed to teach it in order to enhance its easy learning by children; and to avoid misconceptions that might prove difficult to correct later in their academic lives (Cooper \&Tomayko 2011).

To mitigate against this difficulty, children could learn place value better through the use of concrete manipulatives, representational pictures and abstract symbols such as beans or different types of beans, hundred charts, unfix cubes, dice and place value mats (Abella, 2012). Therefore, teachers should consider students' developmental levels when teaching place value because that could affect their understanding of place value (Abella, 2012). For example, such developmental levels could follow logical sequencing of certain skills.

There are several prerequisite skills that the learners must acquire first as they learn the concept of place value to avoid developing misconceptions. These include: a) 
when counting large numbers, it is essential to form groups based on tens, b) groups are counted as single objects, $c$ ) one large group may be made up of many small groups, and that d) a numeral (digit) can stand for different amounts depending on where it is written in the number (Luneta \& Makonye, 2013). Without a proper understanding of such basic skills it might be difficult to introduce high levels of comprehension of place value, and subsequently the number system as a whole. To appreciate the complexity of the concept place value one needs first paint a brief history of how it (place value) evolved over the years. In the next section I therefore spare a few paragraphs to sketch the history of place value. This is intended to shed light on how misconceptions and associated errors in the learning of place value occur.

\section{Misconceptions and associated errors}

There is no agreement among scholars as to whether errors lead to misconceptions or misconceptions lead to errors. This debate has been raging for years (Selden \& Selden, 1987). Studies on the topic cover a wide range of disciplines, such as nutrition (Mahmood, 2012), science and evolution (Wescott \& Cunningham, 2005), to name but a few. In the study of mathematics, the topic has received considerable attention over many years now and volumes of information on it abound (Spooner, 2012; Bosman, 2014).

A useful definition has been that of Hadjidemetriou and Williams (2002), who define error as "erroneous responses to a question" and "caused by insufficient mastery of basic facts, concepts, and skills" (Legutko, 2008, p. 143). Smith, diSessa and Rochelle (1993, p.119) explain that a misconception is a student conception that produces a systematic pattern of error that comes from "the misapplication of a rule, an over- or under-generalization, or an alternative 'conception' of the situation". This could also be part of a faulty cognitive structure that causes, lies behind, explains, or justifies the error."

However, in South Africa, information on this topic remains scarce and isolated. The gap widens even more when it comes to rural schools in provinces such as Limpopo, where performance in mathematics by Grades 3-6 has been consistently dismal in the Annual National Assessment (ANA) (2011-2013) (Department of Basic Education, 2011).

Misconceptions and errors, crudely speaking, occur when locating information in the mind that is not viable or correct either by means of oneself or the person they learnt it from (Mahmood, 2012). Besides relying on a wrong or distorted source of information, a misconception could also arise from applying a rule that is not true under the supposition that it is. For example, the two problems below illustrate the misapplication of the rule by the learner.

a) Multi-digits seen as numbers independent of place value: 83 can be written as $8+3$ instead of $80+3$ (when required to write in expanded form), and 547 as $5+4+7$ instead of $500+40+7$

b) Misapplies the rule for reading numbers from left to right (this difficulty is often caused by teen numbers) as in: 71 could be read as 17; 41 as 14

(the place value concept is lost here). 
When the learner is asked to apply a rule, she/he applies it too generally. This is mainly due to a wrong source acquired earlier. For instance, errors are more general than a misconception as a learner can make an error without assuming something (Bosman, 2014; Spooner, 2012). Thus, an error is doing something incorrectly. For example, implementing an algorithm by transcribing it incorrectly and finding it doesn't work properly. Therefore, an error is a fallacious answer to a question and is induced by scanty prowess of basic concepts, verity and expertise (Sisman \& Aksu, 2016).

In Mathematics errors can be conceptual, veridical, and procedural, and may occur for a number of reasons (Ozkan \& Ball, 2017). Errors that result from misconceptions are illogical to learners as they have developed from the learners' misunderstanding of place value (Ingram, Andrews \& Pitt, 2019). This could explain why Swan (2001) does not regard them as wrong thinking, but as concepts in local generalisation that the student has made. Systematic errors are usually a result of misconceptions. In this study this is the position we adopted.

In sum, we can conclude that a misconception is the result of a lack of understanding or in many cases the misapplication of a rule" or mathematical generalization (Spooner, 2002); whereas an error takes place when a person chooses the false as the truth. When the actual result is different from the objective (erroneous result); when the procedure adopted is different from the accepted procedures (erroneous actions) erroneous conceptions might be hindering problem solving and producing irrational results. Errors are of various types and hence difficult to classify accurately (Spooner, 2012).

Ideas about how students develop misconceptions have been discussed by numerous empirical studies on learning mathematics over the last decade (Makonye \& Hantibi, 2014; Makonye \& Khanyile, 2015). Piaget's repeated demonstration in the late 1970s that children think about the world in very different ways to adults resulted in educational researchers listening carefully to what students were saying and doing on a variety of subject matter tasks (Smith, 1993). What researchers heard and subsequently reported was both surprising and disturbing: students had ideas that competed, often quite effectively, against the concepts presented in the classroom. Students did not come to school as blank slates. They had developed durable conceptions with explanatory power, but those conceptions were inconsistent with the accepted mathematical and scientific concepts presented during instructions (Smith, 1993).

The literature (Makonye \& Khanyile, 2015) has shown many ways in which children's errors in learning place value could be classified. The three most common classifications are: i) systematic errors, ii) random errors and iii) careless errors (Luneta \& Makonye, 2010). The systematic errors are those that occur due to a lack of understanding or incorrect understanding of concepts and principles. Baxter and Dole (1990) correctly put it thus: "Many errors in arithmetical computation are not random or careless; they are learned and have become habitual". Random errors show no discernible relationship to the given problems. Careless errors may be accidental; where the learner may forget to insert a sign (Mohyuddin, 2014). Unfortunately, an expansive discussion on this classification and its cataloguing is beyond the scope of this article. 


\section{Methods used to review this literature}

\section{Searches}

We used three major education search engines: a) EBSCO (British Education Index, Child Development Studies), b) ERIC (Education Resources Information Centre, Teacher Reference Centre) and c) ProQuest (Australian Education Index, Education Database, Education Collection). We combined the following five key words in the searches to maximise the number of potential studies: elementary, mathematics education, primary school, foundation phase place value and multi-digit. We found a total of 50 publications (50 articles, which include reports and 20 books) that were identified and studied. The material included only those abstracts that were available in English

To guide the analysis two research questions were posed:

- What misconceptions and associated errors do learners display in the learning of place value?

- How can learners in Grade 3-6 best be supported to enhance the learning of place value?

Besides the engine searches we also hand searched. The tables of contents of journals that published key articles were hand-searched for relevant studies. Any relevant review papers were hand-searched for relevant references for inclusion. Citations were tracked too, using Scopus.

\section{Data extraction}

Data extracted from the included documents followed the following process:

Coding theme: One-digit place value, two-digit, three-digit place value, primary/elementary mathematics. The study's identification type: qualitative, quantitative and mixed methodology. Journal and author name, publication year, article title, Locality of the study/geographical area, socio-economic status, total number of participants, age range. Key errors.

\section{Quality assurance}

We used two mathematics education studies

We used the following inclusion and exclusion criteria to sift the search for the relevant literature from 1994 to 2019 . We considered this period critical as it marks an epoch of the birth and development of democracy in South Africa. We found this period interesting for two reasons. One, we wanted to see if the new democratic change in South Africa had any impetus in changing performance in Mathematics. Two, we wanted to see if changes in curriculum policy affected the teaching and learning of Mathematics. Thus, studies that did not fall within the ambit, and did not focus on the teaching and learning of numbers were excluded from the review. 


\begin{tabular}{|c|c|c|}
\hline No. & Author (s) & Findings \\
\hline 1 & $\begin{array}{l}\text { Jordan, N. C., Kaplan, D., Nabors Oláh, L., \& } \\
\text { Locuniak, M. N. }\end{array}$ & $\begin{array}{c}\text { Quantitative methodology. } \\
\text { The study examined number sense among children from low-income background who performed } \\
\text { badly }\end{array}$ \\
\hline 2 & $\begin{array}{l}\text { Jordan, N. C., Kaplan, D., Locuniak, M. N., \& } \\
\text { Ramineni, C. }\end{array}$ & $\begin{array}{c}\text { Quantitative methodology. } \\
\text { Kindergarten number competence predicted rate of } \\
\text { growth in mathematics achievement between 1st } \\
\text { and 3rd grades as well as achievement. } \\
\text { Low-income children performed more poorly than their middle-income counterparts in mathematics } \\
\text { achievement } \\
\text { and progressed at a slower rate }\end{array}$ \\
\hline 3 & $\begin{array}{l}\text { Moeller, K., Pixner, S., Zuber, J., Kaufmann, L., \& } \\
\text { Nuerk, H. C. (2011). }\end{array}$ & Early place-value understanding as a precursor for later arithmetic performance \\
\hline 4 & Sari, M. H., \& Olkun, S. (2019). & $\begin{array}{l}\text { Quantitative methodology. } \\
\text { The study was to investigate the relationship between the understanding of the place value } \\
\text { concept, arithmetic performances and mathematics achievement among fourth graders. A strong } \\
\text { relationship appeared between place value conceptions, mathematics achievement and arithmetic } \\
\text { performance of the students. When the place value conception and the arithmetic performances of } \\
\text { students are combined, they explained } 77 \% \text { of the mathematics achievement. Based on these } \\
\text { results, it can be concluded that understanding place value is an important milestone in learning } \\
\text { arithmetic and mathematics in general. }\end{array}$ \\
\hline 5 & Cooper, L. L., \& Tomayko, M. C. (2011) & $\begin{array}{c}\text { Results showed that there were no significant differences between the mathematics achievement, } \\
\text { arithmetic performances and place value conceptions of boys and girls }\end{array}$ \\
\hline 6 & Hertzog, M., Ehlert, A., \& Fritz, A (2019) & $\begin{array}{c}\text { Developing an understanding of place value and the base-ten number system is considered a } \\
\text { fundamental goal of the early primary grades. For years, teachers have anecdotally reported that } \\
\text { students struggle with place-value concepts }\end{array}$ \\
\hline 7 & Kember, D. (2000). & $\begin{array}{l}\text { There is a common perception that Asian students rely upon rote learning and prefer passive forms } \\
\text { of learning, though, this appears to be incompatible with evidence of their high levels of } \\
\text { achievement. This apparent dichotomy is explained by showing that memorisation can occur in } \\
\text { conjunction with the intention to understand. It could also result from students learning material by } \\
\text { heart because they perceive that is what the course and assessment require. }\end{array}$ \\
\hline 8 & $\begin{array}{l}\text { MacDonald, B. L., Westenskow, A., Moyer- } \\
\text { Packenham, P. S., \& Child, B. (2018). }\end{array}$ & $\begin{array}{l}\text { The study was conducted to understand and find out if children in grades } 1-5 \text { are constructing a } \\
\text { system of tens on a system of ones. Only some children in grades } 2-5 \text { evidenced this construction. } \\
\text { Many students engage successfully in mathematics classrooms without having a conceptual } \\
\text { understanding of place value, preventing them from accessing mathematics that is more } \\
\text { sophisticated later }\end{array}$ \\
\hline
\end{tabular}


9

Papadopoulos, I.

Rakes, C. R., \& Ronau, R. N. (2019)

11

Bray (2011)

12

Riccomini, P. J. (2005).

Cai (1995)

The findings show that in this specific rural environment and via appropriate tasks teachers are provided with a context to better understand what year 5 or 6 pupils know or do not know about place value and how they are able to apply their understanding of place-value and the use of operations in this particular context.

Multiple foundational structures were found to be related to misconceptions in each content domain, and misconceptions for multiple content domains were found within each foundational structure. The quantitative analyses found that the best classification of misconceptions included correlations among the content domains and a factor independent of content domain. The qualitative analyses led to the conclusion that interactions among the foundational knowledge structures best described the factor independent of content domain.

This collective case study examines the influence of 4 third-grade teachers' beliefs about and knowledge of their error-handling practices during a class discussions of mathematics.

Study findings suggest that, although teachers' ways of handling student errors during class discussions of mathematics are clearly linked to both teacher beliefs and teacher knowledge, some aspects of teacher response are more strongly linked to either knowledge or more to beliefs.

The present study investigated 90 elementary teachers' ability to identify two systematic error

patterns in subtraction and then prescribed an instructional focus. An analysis of the data indicated teachers were able to describe specific error patterns. However, they did not base their instructional focus on the error patterns identified, and more than half of the teachers chose to address basic subtraction facts first during instruction regardless of error type.

The study sought to examine multi-choice tasks assessing complex problem solving for Grade 6

Chinese and US children. The study found the Chinese to perform significantly better than the US children. But on the subsets the US children performed better that the Chinese children. This suggests the complexity of examining performance of differences and the inadequacy of using a limited range of tactics to measure mathematical difference

The study examined the connection between teaching and development,

focusing in particular on how children solve "missing addend" story problems, when second

Brissiaud, R. (1994).

graders are forced to solve a problem of this type by choosing an arithmetic operation ( + or - ), half of them fail. The most frequent error is choosing addition. The subjects in the experiment presented here were second graders who had always been given the opportunity to use drawings and manipulatives and forward strategy to solve subtraction problems. Learners struggled.

15 Ohlsson, S., \& Rees, E. (1991).

MacDonald, A. (2008).
This study found that learners tend to solve their arithmetic problems algorithmically rather than conceptually

A common misconception among students about decimal place value is discussed, with reference to the examination response of a Year 7 student who thought the first place after the decimal point had the value 'oneths'. The implications of the 'oneths' misconception for teaching practice and suggestions to help students overcome the problem are discussed. 
The purpose of this descriptive study is to investigate why some elementary children have difficulties mastering addition and subtraction calculation tasks. 17 Watson, JM., Loes, J, Oliveira, C \& Judge S (2018) $\begin{aligned} & \text { Students' errors suggested that their performance in calculation tasks is related to conceptual and } \\ & \text { procedural knowledge and skills. Error analysis allows teachers to better understand the individual }\end{aligned}$ performance of a diverse group and to tailor instructions to ensure that all students have an opportunity to succeed in mathematics.

Children exposed and using HiWEL LSs pick up academic English and mathematics on their own

18 Dangwal, R., Sharma, K. and Hazarika, S. (2014) for grades 6 and 7. Qualitatively, the teachers and parents feel that they too have seen the benefits in the academic achievement of these children.

\begin{tabular}{|c|c|c|}
\hline 19 & Fang, Y., Lee, C.K.E. and Yang, Y. (2012). & $\begin{array}{l}\text { A video documentary traces the research problem and how teachers learned to use the concrete- } \\
\text { pictorial-abstract (CPA) model to improve teaching for student learning. }\end{array}$ \\
\hline 20 & Chatterji, M. and Lin, M. (2018). & $\begin{array}{c}\text { Survey } \\
\text { The purpose of this study was to design and iteratively improve the quality of survey-based } \\
\text { measures of three non-cognitive constructs for Grade 5-6 students, keeping in mind the information } \\
\text { needs of users in education reform contexts. At both student and classroom levels, replicated } \\
\text { evidence supported theoretically-grounded validity arguments on information produced by four of } \\
\text { five scales tapping M-SC, M-ANX and M-SE. }\end{array}$ \\
\hline 21 & Herzog, M., Ehlert, A., \& Fritz, A. (2019). & $\begin{array}{c}\text { A resilient understanding of the decimal place value system is a crucial element of primary } \\
\text { mathematical education that has a significant impact on further arithmetical development. Place } \\
\text { value understanding has been identified as a good predictor of math performance as well as math } \\
\text { difficulties. Difficulties in understanding the place value system affects children to different degrees } \\
\text { in countries all over the world. }\end{array}$ \\
\hline 22 & Griffin, L. B. (2016). & $\begin{array}{c}\text { The author proposes strategic instructional choices that simultaneously address common decimal } \\
\text { misconceptions and help students race toward decimal understanding }\end{array}$ \\
\hline 23 & Sisman, G. T., \& Aksu, M. (2016). & $\begin{array}{c}\text { The findings revealed a wide range of misconceptions and errors such as "believing that all rulers } \\
\text { are } 30 \mathrm{~cm} \text { long," "confusing area formula with perimeter formula," "believing a box has more than } \\
\text { one surface area," "using the volume formula for surface area," "believing that a ruler must be } \\
\text { longer than the object measured. }\end{array}$ \\
\hline
\end{tabular}




\section{Results}

The purpose of this article was to conduct a systematic review of literature on place value as an aspect of number sense in young children (Grades 3-6). We examined how place value has been studied elsewhere in the world, and South Africa in particular, in the past 30 years (1990-2020). Specifically, we focused on the methodological characteristics and publication trends on the study of place value. We used a documentary review design where a total of 20 articles from empirical studies were reviewed. Overall the findings from these studies indicate that children struggle with learning place value, and they need support. However, upon close scrutiny, wide spectrum of issues that can be grouped into seven broad themes a wide spectrum emerges. In the next section we will address these themes briefly.

\section{Theme 1: Low socio-economic status and context}

Examining performance we could only find reference to perroamnce differences is a complex and a difficult task (Kamii,1986). Therefore, studies that attempt to do that are few and dispersed. However, in our search we found two studies that attributed difficulties in learning place value by children to their socio-econmic status (SES) (Study 2) (Jordan, Kaplan, Nabors Oláh \& Locuniak, 2006). In this study, like others who factor in their analysis found that children who come from low SES found it difficult to understand and master place value. Traditions in the homeland that illuminate the roots of cultural values and practices that are conducive to school success struggle with place value (Siu, 1992) (Studies 9,20).

\section{Theme 2: Good early understanding is a precursor for later mathematics}

The second theme that emerged from our reviews is the fact that a good place value conception in early grades is related to good mathematics later on. Studies found that understanding place value is an important milestone in learning arithmetic and mathematics in general (Studies 4) (Sari \& Olkun, 2019). However, contrary to this finding, Cooper and Tomayko (2011) (Study 5) did not find such an association. Only one study found no significant relationships between a good understanding of place value and mathematics performance (Study 5). But, their study finds no support in the majority of studies that hold this view (Moeller, Pixner, Zuber, Kaufmann \& Nuerk, 2011; MacDonald, Westenskow, Moyer-Packenham, \& Child, 2018). Based on these results, it can be concluded that understanding place value is an important milestone in learning arithmetic and mathematics in general (Herzog, Ehlert \& Fritz, 2019).

\section{Theme 3: Students learn place value without conceptual understanding}

Our review found that children were learning place value algorithmically rather than conceptually. Studies (Ohlsson \& Rees, 1991; MacDonald, Westenskow, MoyerPackenham \& Child, 2018) (Studies 8 and 15) aslo found the same. We agree with a number of studies (Russell \& Chernoff, 2013; McGarve \& McFeetors, 2013; Luneta \& Makonye, 2013; Haylock \& Cockburn, 2013) which conclude that they have found the problem why children dislike mathematics. It is because teachers teach it by bombarding them with rules without any explanation. 


\section{Theme 4: Teacher beliefs and knowledge}

This theme appears to be an isolated case; mainly because it focuses more on teachers than learning as a unit of analysis. However, we included it here because we thought that teachers play an important role in influencing how learners learn and teachers can support them (Bray, 2011). Future studies may find this trajectory interesting to study.

\section{Theme 4: Misconceptions and errors}

Our findings confirm that a large body of literature (Aksoy \& Yazlik, 2017; Lestiana, Rejeki, \& Setyawan, 2017; Nuraini, Cholifah \& Laksono, 2018; Deringöl, 2019) has paid attention to the study of misconceptions and errors. Learners' misconceptions and associated errors while learning mathematics are considered as rich vehicles for uncovering their conceptualisation, ways of thinking, and learning difficulties (Greeno, Collins \& Resnick, 1996). Therefore, their understanding is critical to the successful teaching of place value. Study 16 in table 1 above points out that common misconceptions and errors among learners were about decimal place value, that is, they think that the first place after the decimal point had the value 'oneths'. The second common type of error was miscalculation for both addition and subtraction. The third most common error type was related to the failure to regroup in addition and subtraction (Watson, Loes, Oliveira \& Judge, 2018).

\section{Theme 6: The use of manipulatives}

One other common theme that emerged from our findings is that children appear to learn place value better through manipulatives such as cuttings, drawings, unifix tubes, colour tiles, base ten blocks, and others rather than by mental mathematics. For example, the study by Dangwal, Sharma and Hazarika (2014) indicates that when children use the computer Hole-in-the-Wall (HiWEL)" programme to learn place value, among other things, their performance improved. Further, a study by Fang, Lee and Yang (2012) shows that where videos were used to teach results improved.

\section{Discussion}

The purpose of this systematic review of literature was to examine research studies on how place value has been studied in the past 25 years (1995-2020), worldwide, and with particular reference to South Africa. Specifically, we focused on the methodological characteristics and publication trends in the study of place value. This focus translated into three questions that guided the search and analysis of the literature: a) what do we know about the types of misconceptions and associated errors displayed by Grade 3-6 in the learning of place value so far? b) How has place value been studied elsewhere in the world, and South Africa in particular, in the last 25 years? c) How best have these learners been supported to enhance their understanding of place value? This review argues that problems associated with the learning of place value can only be understood within the historical perspective.

In response to the first question, we found that the common misconceptions and errors could be classified into four types, namely: a) rote learning and memorisation, b) careless errors, c) conceptual errors and e) application. Our finding is consistent with other studies (Clements, 1982; Hodes \& Notting, 1998; Luneta \& Makonye, 2010; Luneta \& Mdaka, 2011). The problem with these types of misconceptions and 
errors seems to be a long-standing problem. Teachers need to know this if they are to support learners in their learning of place value. Surprisingly, despite its importance, this topic has received little attention in the lower grades. The last comprehensive study on misconceptions and associated errors was in 1989 by Murray and Oliver (1989). It made a profound contribution to children's understanding of two-digits and their proposed model of numeration and computation. Other studies on misconceptions and associated errors in South Africa (Luneta \& Makonye, 2010; Luneta \& Mdaka, 2011; Makonye \& Hantibi, 2014; Herholdt \& Sapire, 2014, Dhlamini \&Kibirige, 2014) have been limited to the higher grades.

In response to the second question, we observed that the problem has been studied for many years (Sari \& Olkun, 2019). Since then there has been a large body of literature on the subject. Regarding the period we covered (1995-2020), impressive work has been done as reflected in Table 1 (Study 6). However, we think that there is a paucity of studies that link this problem to historical perspectives. Theme 1 points to this scarcity. The gap becomes even wider when it to comes to South Africa. It has a appalling historical inequalities that impinge upon the learning of mathematics.

Concerning the third question, the majority of studies in Table 1 above shows a bent pattern towards quantitative, mostly survey studies. This implies that most studies have been on and about children and not with them. This negligence has meant that children have been left out of things that affect their learning.

Other variables that are missing include comparative studies on gender, age, and children who experience barriers to learning.

Pertaining to the last question, not much has been done in this area. However, most studies offer some useful suggestions on how children can best be supported to learn place value; for example, the use of manipulatives such as videos and computers, and other things. Learners need enriched environments, especially those from impoverished backgrounds.

children's mathematics, so their teaching of place value will improve.

\section{Implications of this study}

The study has at least three implications. One, for policymakers, the review though limited in its scope and depth, might provide invaluable insights into what is available in the study of place value. This information may be useful in planning interventions. Two, teacher education institutions may provide lessons for educators on how to prepare teachers to teach place value better. As teacher education institutions improve their curriculum for children's mathematics so that their teaching of place value is improved Last but not least, teachers may benefit from these findings in their classrooms as they battle to teach place value better.

\section{Conclusion}

In general, systematic reviews are scarce across all fields, but more so in the study of place values as this study has shown. There is a need for more studies of this kind to close this gap. Here we have merely scratched the surface by indicating that the learning of place value needs more attention than is given at the moment. 


\section{References}

Aksoy, N. C., \& Yazlik, D. O. (2017). Student errors in fractions and possible causes of these errors. Journal of education and training studies, 5(11), 219-233.

Benton, L., Saunders, P., Kalas, I., Hoyles, C., \& Noss, R. (2018). Designing for learning mathematics through programming: A case study of pupils engaging with place value. International journal of child-computer interaction, 16, 68-76.

Bray, W. S. (2011). A collective case study of the influence of teachers' beliefs and knowledge on error-handling practices during class discussion of mathematics. Journal for Research in Mathematics education, 42(1), 2-38.

Brissiaud, R. (1994). Teaching and development: Solving "missing addend" problems using subtraction. European Journal of Psychology of Education, 9(4), 343-365.

Cai, J. (1995). A cognitive analysis of US and Chinese students' mathematical performance on tasks involving computation, simple problem solving, and complex problem solving. Journal for Research in Mathematics Education. Monograph, i-151.

Chatterji, M. and Lin, M. (2018), "Designing non-cognitive construct measures that improve mathematics achievement in Grade 5-6 learners: A user-centred approach", Quality Assurance in Education, Vol. 26 No. 1, pp. 70-100.

Coles, A. L. F., \& Sinclair, N. (2017). Re-thinking place value: From metaphor to metonym. For the learning of mathematics, 37(1), 3-8.

Cooper, L. L., \& Tomayko, M. C. (2011). Understanding Place Value. Teaching children mathematics, 17(9), 558-567.

Cox (1975) System Errors in the four algorithms in normal and handicapped populations. Journal for Research in Mathematics Education, vol. 6 No.4 pp. 202220.

Dangwal, R., Sharma, K. \& Hazarika, S. (2014), "Hole-in-the-Wall learning stations and academic performance among rural children in India. Journal of Multicultural Education 12 (1), 67-82.

Fang, Y., Lee, C.K.E. \& Yang, Y. (2012), "Developing curriculum and pedagogical resources for teacher learning: A lesson study video case of "Division with Remainder" from Singapore", International Journal for Lesson and Learning Studies 1(1), 65-84.

Greeno, J. G., Collins, A. M., \& Resnick, L. B. (1996). Cognition and learning. Handbook of educational psychology, 77, 15-46.

Griffin, L. B. (2016). Tracking decimal misconceptions: Strategic instructional choices. Teaching Children Mathematics, 22(8), 488-494.

Haylock, D., \& Cockburn, A. D. (Eds.). (2013). Understanding mathematics for young children: A guide for teachers of children 3-8. Sage

Herzog, M., Ehlert, A., \& Fritz, A. (2019). Development of a Sustainable Place Value Understanding. In International Handbook of Mathematical Learning Difficulties (pp. 561-579). Springer, Cham.

Kamii, C. (1986). Place value: An explanation of its difficulty and educational implications for the primary grades. Journal of Research in Childhood Education, 1(2), 75-86.

Kember, D. (2000). Misconceptions about the learning approaches, motivation and study practices of Asian students. Higher education, 40(1), 99-121.

Lestiana, H. T., Rejeki, S., \& Setyawan, F. (2017).

Luneta, K (2013). Teaching Elementary Mathematics. Learning to teach elementary mathematics through mentorship and professional. Germany: Lambert Academy. 
Luneta, K., \& Makonye, J. P. (2013). Learners' mathematical errors in introductory differentiation: A theoretical framework. US-China Education Review, 3(12), 914-923. MacDonald, A. (2008). 'But What about the Oneths?': A Year 7 Student's Misconception about Decimal Place Value. Australian Mathematics Teacher, The, 64(4), 12.

MacDonald, B. L., Westenskow, A., Moyer-Packenham, P. S., \& Child, B. (2018). Components of Place Value Understanding: Targeting Mathematical Difficulties When Providing Interventions. School Science and Mathematics, 118(1-2), 17-29.

Moeller, K., Pixner, S., Zuber, J., Kaufmann, L., \& Nuerk, H. C. (2011). Early placevalue understanding as a precursor for later arithmetic performance-A longitudinal study on numerical development. Research in developmental disabilities, 32(5), 18371851.

Rakes, C. R., \& Ronau, R. N. (2019). Rethinking Mathematics Misconceptions:

Using Knowledge Structures to Explain Systematic Errors within and across Content Domains. International Journal of Research in Education and Science, 5(1), 1-21.

Riccomini, P. J. (2005). Identification and remediation of systematic error patterns in subtraction. Learning Disability Quarterly, 28(3), 233-242.

SARI, M. H., \& OLKUN, S. (2019). The relationship between place value understanding, arithmetic performance and mathematics achievement in general. Elementary Education Online, 18(2).

Siu, S. F. (1992). Toward an Understanding of Chinese-American Educational Achievement: A Literature Review. Report No. 2.

Sisman, G. T., \& Aksu, M. (2016). A study on sixth grade students' misconceptions and errors in spatial measurement: Length, area, and volume. International Journal of Science and Mathematics Education, 14(7), 1293-1319.

Watson, JM., Loes, J, Oliveira, C \& Judge S (2018). Error patterns in Portuguese students' addition and subtraction calculation tasks: Implications for teaching. Journal of Multicultural Education 8 (1), 31-53.

Winter, E., \& O'Raw, P. (2010). Literature review of the principles and practices relating to inclusive education for children with special educational needs. National Council for Special Education. Trim, Northern Ireland. 